\title{
STUDY OF INHIBITORY EFFECT OF EXTRACT OF TURMERIC (CURCUMA LONGA) ON STAPHYLOCOCCUS AUREUS
}

\section{Kumar R, Bhattacharyya S*, Singh S, Sarfraz A, Kumar D, Sengupta A, Kumar A, Jaiswal NK. Department of Microbiology, AlIMS, Patna-801507, Bihar, India.}

\begin{abstract}
Staphylococcus aureus is a smart pathogen, capable of causing many different infections. It is often resistant to available antibiotics like Oxacillin, macrolides, and aminoglycosides. This necessitates the discovery of newer classes of molecules and naturally derived compounds to tackle this pathogen. We here present the inhibitory effect of turmeric, a common kitchen ingredient, on growth, multiplication and virulence factors of Staphylococcus aureus.
\end{abstract}

Keywords: Staphylococcus aureus, turmeric, inhibition.

\section{INTRODUCTION}

Staphylococcus aureus, a gram-positive pigmented coccus, is a commensal flora of human skin and mucosa, and is also associated with multiple infections(1). Approximately 30-40\% people are carriers of $S$. aureus in the nasopharynx and other sites (2). It is a vicious pathogen possessing numerous important virulence factors like golden yellow pigment (carotenoids), adhesive matrix molecules, superantigens, cytolysins, lipases and proteases(3). Drug resistance is a problem in $S$. aureus, with Methicilin-resistant Staphylococcus aureus predominating in the hospital acquired bacterial infections as well as in community scenario(4). So the need of the hour is the development of newer drugs and molecules that can inhibit this pathogen. Turmeric (Curcuma longa) is a common kitchen ingredient that has known anti-inflammatory, antioxidant and antiinfective properties(5).

\section{INTRODUCTION}

To study the effects of turmeric aqueous extract on growth and virulence traits of Staphylococcus aureus. The objective of the study was a) To grow and identify $S$. aureus from samples, b) To test the efficacy of Peptone water with $4 \%$ and $8 \%$ (weight/volume) on growth, structure, lipase, lecithinase and protease of $\mathrm{S}$.

*Corresponding author:

Email: sayantheboss@yahoo.co.in

http://dx.doi.org/10.20530/IJTA_32_38-40

ISSN 2320-138x @ 2016 aureus and c) To test the toxicity of turmeric extract on host RBC and WBC.

\section{MATERIALS AND METHODS}

This was a laboratory-based observational study carried out in Department of Microbiology of the Institute from December 2014 to December 2015.

S. aureus was identified from samples of pus, urine and sputum using Gram stain morphology, mannitol fermentation and positive catalase and slide coagulase tests (using pooled human plasma). Ten (10) different S. aureus isolates were randomly chosen for the study.

Raw turmeric was obtained from market (from 3 different sources). In 2 sets, 4 grams and 8 grams of smashed turmeric root was mixed in Peptone water and autoclaved at $121 \mathrm{deg} C$ for 15 minutes at $15 \mathrm{lbs} / \mathrm{in}^{2}$ pressure. After that, they were cooled, and 2-3 colonies from $S$. aureus isolates were inoculated in (a)Peptone water, and (b)Peptone water with turmeric extract. They were then incubated at $37{ }^{\circ} \mathrm{C}$ overnight. After that 1 loopful from each was subcultured on Egg yolk agar. Phospholipase (lecithinase) activity on egg yolk agar was defined by haziness around colonies while protease was defined as clearing around colonies. Lipase on egg yolk agar was defined by shiny colonies. Forty microliters from each tube was put on the slide, made into wet mount and examined for a reduction in cell count or alteration of cell shape. Gram stain was also done and observed, from the broths. The liquid content of each tube was discarded, and tubes were washed 
thrice with sterile normal saline. Then $2 \mathrm{ml}$ aqueous safranin $(0.5 \%)$ was poured into each test tube, kept for 1 minute and washed thrice with sterile normal saline. Following this, the tubes were kept in inverted position and stained biofilms observed manually on the inner wall of tubes(6).

For toxicity assay, 1 drop of peptone water with turmeric was mixed with 1 drop of buffy coat and packed cell concentrate, respectively in 2 different sets, and made into a wet mount. This was observed for 15 minutes under 40X microscope power to see for any destruction of RBCs and WBCs by the turmeric extract.

All, tests were done three times.

\section{RESULTS}

Turmeric extract inhibited cell wall development in S. aureus since $S$. aureus is stained red (Gram negative) when the stain was made after incubation in turmeric extract. Wet mount assay revealed that cell count was decreased by turmeric extract, possibly by inhibiting bacterial multiplication. In egg yolk agar, it was seen that lecithinase and protease, along with golden yellow pigment of $S$. aureus, was inhibited by turmeric extract. Colony count was however, not significantly reduced on egg yolk agar subculture after incubation in turmeric extract $(p>0.05$ by $Z$ test).

The extract was completely non-toxic to human RBCs and WBCs.

\section{DISCUSSION}

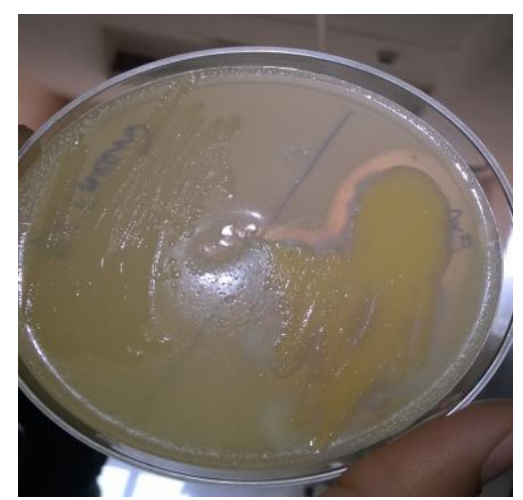

Fig. 1

Staphylococcus aureus infections can be very difficult to identify because of the frequent occurrence of atypical variants, and is also difficult to treat(7). It is a deadly pathogen for both community-acquired and nosocomial infections, and MRSA (Methicillin-resistant Staphylococcus aureus) is endemic in India(8). Turmeric, an ingredient of Indian cuisine since antiquity, has also been documented to have antibacterial effects on bacteria like Escherichia coli and Vibrio cholera(9). The major curcuminoid in turmeric is called curcumin (diferuloylmethane), which makes up about $90 \%$ of the curcuminoid content in turmeric, followed by demethoxycurcumin and bisdemethoxycurcmin(9). Our study shows for the first time that the effects of turmeric extract on Staphylococcus aureus are on its cell wall and hydrolytic enzymes like protease and phospholipase. It also inhibits multiplication but not significantly. This can pave the way for the discovery of new antibiotic compounds to treat infection due to this bacterium. Since autoclaved extract was used, the effect was due to heat stable compounds, indicating that the inhibitory effect could be of use in fertile states also. All these findings are of great interest.

\section{ACKNOWLEDGMENT}

The authors acknowledge the help of Mahesh Kumar, lab attendant in preparing extracts and media.

\section{REFERENCES}

1. Cogen AL, Nizet V, Gallo RL. Skin microbiota: a source of disease or defence? British Journal of Dermatology. 2008 Feb 11;158(3):442-55. Available from: http://dx.doi.org/10.1111/j.13652133.2008.08437.x.

2. Plata K, Rosato AE, Wegrzyn G. Staphylococcus aureus as an infectious agent: overview of biochemistry and molecular genetics of its pathogenicity. Acta Biochim Pol. 2009;56(4):597612. Epub 2009 Dec 11. Review. PubMed PMID: 20011685

3. Jarraud S. Relationships between Staphylococcus aureus Genetic Background, Virulence Factors, agr Groups (Alleles), and Human Disease. Infection and Immunity; 2002 Feb 1;70(2):631-41. Available from: $\quad$ http://dx.doi.org/10.1128/iai.70.2.631$\underline{641.2002}$

4. Factsheet: Methicillin Resistant Staphylococcus aureus:

http://www.cfsph.iastate.edu/Factsheets/pdfs/mrs a.pdf.2014.

5. Sood S, Nagpal M. Role of curcumin in systemic and oral health: An overview. J Nat Sc Biol Med. 2013;4(1):3. Available from: http://dx.doi.org/10.4103/0976-9668.107253. 
6. Katsikogianni M, Spiliopoulou I, Dowling DP, Missirlis YF. Adhesion of slime producing Staphylococcus epidermidis strains to PVC and diamond-like carbon/silver/fluorinated coatings. Journal of Materials Science: Materials in Medicine; 2006 Aug;17(8):679-89. Available from: http://dx.doi.org/10.1007/s10856-006-9678-8.

7. Vaudaux P, Kelley WL, Lew DP. Editorial Commentary: Staphylococcus aureus Small Colony Variants: Difficult to Diagnose and Difficult to Treat . CLIN INFECT DIS. 2006 Oct 15;43(8):968-70. Available from: http://dx.doi.org/10.1086/507643.
8. Joshi S, Ray P, Manchanda V, Bajaj J, Chitnis DS , Gautam V et al. Methicillin resistant Staphylococcus aureus (MRSA) in India: Prevalence \& susceptibility pattern. Indian J Med Res; 2013;137:363-69.

9. Selvam RM, Singh AJAR, Kalirajan K. Antifungal activity of different natural dyes against traditional products affected fungal pathogens. Asian Pacific Journal of Tropical Biomedicine; 2012 Jan;2(3):S1461-S1465. Available from: http://dx.doi.org/10.1016/s2221-1691(12)60438-9 